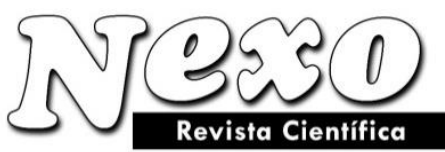

Vol. 34, No. 01, pp. 13-23/Marzo 2021

\title{
Size effects in ultrafine iron. New structures: 2D - 3D
}

\section{Efectos de tamaño en de hierro ultrafino. Nuevas estructuras: 2D - 3D}

\author{
Yuriy V. Baldokhin ${ }^{1, *}$, Yuriy D. Perfiliev ${ }^{2}$, Leonid A. Kulikov ${ }^{2}$ \\ ${ }^{1}$ Semenov Institute of chemical physics, Russian Academy of Sciences, Russian Federation. \\ ${ }^{2}$ Lomonosov Moscow State University, Chemical Department, Russian Federation. \\ *perf2008@live.ru
}

(recibido/received: 15-October-2020; aceptado/accepted: 25-November-2020)

\begin{abstract}
This article is devoted to the analysis of the size of iron nanoparticles impact on the structure, to comparison of the results obtained for the nanopowders in the various authors' researches. The article considers factors that may impact on the form and parameters of the Mössbauer spectra of iron nanopowders obtained by the inert gas condensation technique (Gen-Miller's method). Possible causes of the new state of the iron are proved with the effective magnetic field at the $57 \mathrm{Fe}$ nucleus $(\mathrm{H}=365 \mathrm{kOe})$. But the results related to size effects differ from the researches of other authors. It was revealed that nanoparticles with a mean (X-ray data) particle size of $50 \mathrm{~nm}$ have also Angstrem patterns, which can meet the new structure. Presence of small amounts of superparamagnetic oxide could be a catalyst, impetus for the formation of the new structure, and also, at the exchange interactions, could modify the charge of the electron density at the Fe nuclei. Reviewed and other factors can result in appearing of such a high value of the effective magnetic field at the iron nuclei.
\end{abstract}

Keywords: Electron microscopy, Iron, Mössbauer spectroscopy, Nanoparticles, New state of iron.

\section{RESUMEN}

Este artículo se dedica al análisis del impacto del tamaño de nanopartículas de hierro en su estructura y a la comparación de los resultados obtenidos para los nanopolvos en estudios llevado a cabo por autores diferentes. Aquí también se consideran los factores que pueden afectar la forma y los parámetros de los espectros Mössbauer del nanopolvo de hierro producido por medio de condensar el gas inerte (método Gen-Miller). Se demuestran las causas posibles del estado nuevo del hierro a través de un campo magnético efectivo para el nucleo de $57 \mathrm{Fe}(\mathrm{H}=365 \mathrm{kOe})$. Pero los resultados relacionados a efectos del tamaño son diferentes de lo obtenido por otros autores. Se revela que los nanopartículas del tamaño medio de $50 \mathrm{~nm}$ (datos de examinaciones con rayos $\mathrm{X}$ ) también tienen modelos Angstrem que pueden corresponden a la estructura nueva. La ocurrencia del óxido superparamagnético en cantidades pequeñas puede catalizar la formación de la estructura nueva y también, en caso de interacciones de intercambio, modificar la carga de la densidad del electrón en el núcleo de Fe. Los factores examinados y otros factores pueden resultar en la generación del campo magnético de un alta intensidad alrededor del núcleo de hierro.

Palabras clave: Microscopía electrónica, Hierro, Espectroscopia Mössbauer, Nanopartículas, Estado nuevo de hierro. 


\section{INTRODUCTION}

Ultrafine iron particles with an average size of 10-100 $\mathrm{nm}$ are usually in random motion due to their high surface energy, which is a result of uncompensated relationships of atoms at the surface. Ultrafine particles are pyrophoric, they actively interact with each other and the environment, i.e. mainly with oxygen. At atmospheric pressure the core particles of iron, even when special means of protection, are covered by oxides. Because of the dynamics of ultrafine particles of iron Mössbauer transmission spectra of gamma quanta with an energy of $14.4 \mathrm{Kev}$ with a simple powder filling have a very small effect. When powders pressurized, the effect can be significantly increased. Sometimes glue or other binder are used to bind the particles. The degree of preparation of the samples determines the differences in Mössbauer spectra. Mössbauer spectra of the nanoparticles obtained by chemical, electro-explosive or other methods often differ from spectra of nanoparticles prepared by gas evaporation.

In some studies samples of iron nanopowders are obtained by evaporation of high-purity metallic iron in high-purity argon in the pressure range of 0.5-20 Torr and evaporation rate of 0.5-5 $\mathrm{mg}$ per minute were studied. The average particle size is $6-100 \mathrm{~nm}$, depending on the gas pressure and the rate of evaporation. Thus, Hayashi et al. (1980) considered the effects of fluctuations in the iron lattice of particles with a diameter of 10 and $15 \mathrm{~nm}$, obtained by the inert gas evaporation method. The value of Debye temperature was $470 \mathrm{~K}$. The particles had a surface oxide layer thickness of 1-2 monolayer, which in the spectra at 295 $\mathrm{K}$ manifested in the "sagged wire" form, that meets fields from the ultra-small particles (fields decreased with decrease in particle size to sizes smaller than $10 \mathrm{~nm}$ ). At $85 \mathrm{~K}$ such oxide particles turned into magnetite.

Herr et al. (1987) studied iron particles of sizes 1-10 nm, also obtained by gas evaporation. The authors have obtained at $77 \mathrm{~K}$ sextet with two fields: $\mathrm{H}=343 \mathrm{kOe}(\mathrm{BCC}$ iron) and $\mathrm{H}=351 \mathrm{kOe}$. Last sextet had a 5 times wider line than the first (such a wide line arises, if the powders previously were poorly compacted). Both sextets had a positive chemical shift, which could be due to the presence of oxygen in a bound or adsorbed form. Spectrum measured at $295 \mathrm{~K}$ is not presented in the article; however, the analysis of the field strength Heff dependence on the temperature shows that in the spectrum there should be only one sextet, corresponding to the normal Fe. The presence of a sextet with a large field $351 \mathrm{kOe}$ at $77 \mathrm{~K}$ the authors attributed to the new structure due to the presence of boundary, interface areas.

Almost the same model is proposed by Pollard \& Chadwick (1994) and Campbell et al. (1995) for nanopaste obtained by condensation in the gas. But in these studies, after compaction of the iron particles at room temperature signs of the existence are only weakly expressed in the spectrum of the second sextet in the "sagged wire" form. At $200 \mathrm{~K}$ spectrum has one broad sextet, which the authors divided into 2 sextets with narrow and broad lines. At $4.2 \mathrm{~K}$ the spectrum is again almost identical to the spectrum at 200 $\mathrm{K}$, but it reflects the lines corresponding to traces of oxides.

It's worth to mention the study by Bianco et al. (1997), who, after mechanical alloying of iron powders with an average grain size of 8,19 and $25 \mathrm{~nm}$ in addition to the field strength of the $\mathrm{H}=330 \mathrm{kOe}$ received fields which are less than $330 \mathrm{kOe}$. The authors also considered these fields as the structure of grain boundaries, the presence of interface areas. This article is devoted to the analysis of the size of iron

nanoparticles impact on the structure, to comparison of the results obtained for the nanopowders in the various authors' researches.

\section{MATERIALS AND METHODS}

The Mössbauer transmission spectroscopy technique was used in the experiment. Measurements were performed at $293 \mathrm{~K}$ and $77 \mathrm{~K}$. The Mössbauer source (in the rhodium matrix) activity of $35 \mathrm{mCu}$ also was used. Statistics was collected continuously for 65 hours. The measurements were conducted with 
Mössbauer spectrometer MS-1104 (Russia). Electron microscopic studies were performed on a transmission electron microscope JEM-2100 F, Jeol (Japan).

\section{RESULTS AND DISCUSSION}

In Semenov Institute of Chemical Physics, Academy of Sciences of the USSR, in the early 60 -ies of the last century the inert gas evaporation method (Gen - Miller's method) was developed to obtain ultrafine particles of metals and alloys. The study of nano-powders of iron and its alloys was carried out in papers of Baldokhin (1992), Petrov (2001), Shafranovsky et al. (1998). by evaporation of high-purity carbonyl iron in levitation jet generator of fine particles at a pressure of argon of about 1 atmosphere prepared particles with an average size of 35 and $50 \mathrm{~nm}$. one hyperfine field $\mathrm{H}=330 \mathrm{kOe}$ responsible $\mathrm{Fe}$ was found in the $35 \mathrm{~nm}$ particles. But in the spectra of samples of size $50 \mathrm{~nm}$ there were two of the sextets with effective fields $\mathrm{H}=330 \mathrm{kOe}(37.8 \%)$ and $\mathrm{H}=366 \mathrm{kOe}(62.2 \%)$ and traces of paramagnetic peak. Magnetic field with the value $\mathrm{H}=366 \mathrm{kOe}$ explains the "freezing" during rapid quenching of high-temperature ferromagnetic spin state of the face centered cubic structure of iron (Weiss theory). Traces of paramagnetic peak can respond to high temperature (antiferromagnetic) electronic configuration of $57 \mathrm{Fe}$ atoms. By X-ray data (Fig.1), impurities were found, additionally was could see only range of Scotch mount powder.

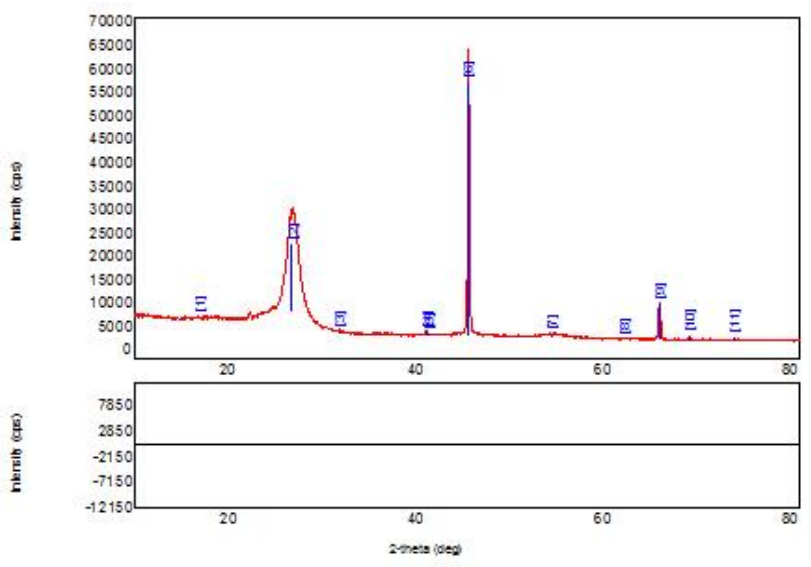

Figure 1. X-ray spectra of samples of ultrafine iron with a particle size of $50 \mathrm{~nm}$.

The lattice parameter was $0.286395 \mathrm{~nm}$. Diffraction spectra indicated the presence of only one structure of BCC iron, which in Mössbauer spectra corresponds to the field strength of the $\mathrm{H}=330 \mathrm{kOe}$. After long exposure (aging sample with a particle size of $50 \mathrm{~nm}$ at room temperature for more than 20 years) spectrum consisted of two distinct, clearly separated sextets, the structure became more ordered. Results on X-ray spectra of powder sample with a particle average size of $50 \mathrm{~nm}$ and $35 \mathrm{~nm}$ in narrow range of the angles are summarized in Fig. 2a and 2b (small changes). 


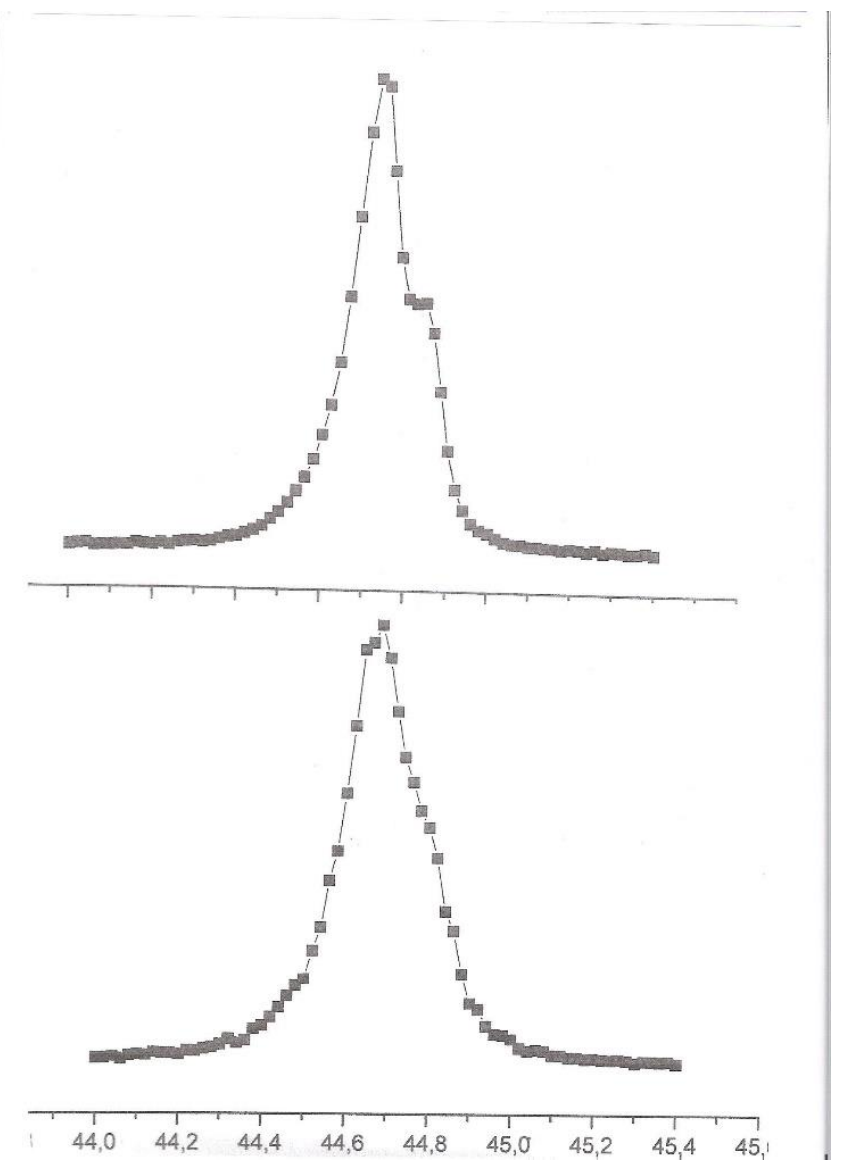

Figure 2. X-ray spectra of samples of ultrafine iron with a particle size of $50 \mathrm{~nm}$ and $35 \mathrm{~nm}$.

Mössbauer absorption spectra of samples of ultrafine iron with a particle size of $50 \mathrm{~nm}$ (a) and $35 \mathrm{~nm}$ (b) shown in Fig. 3.
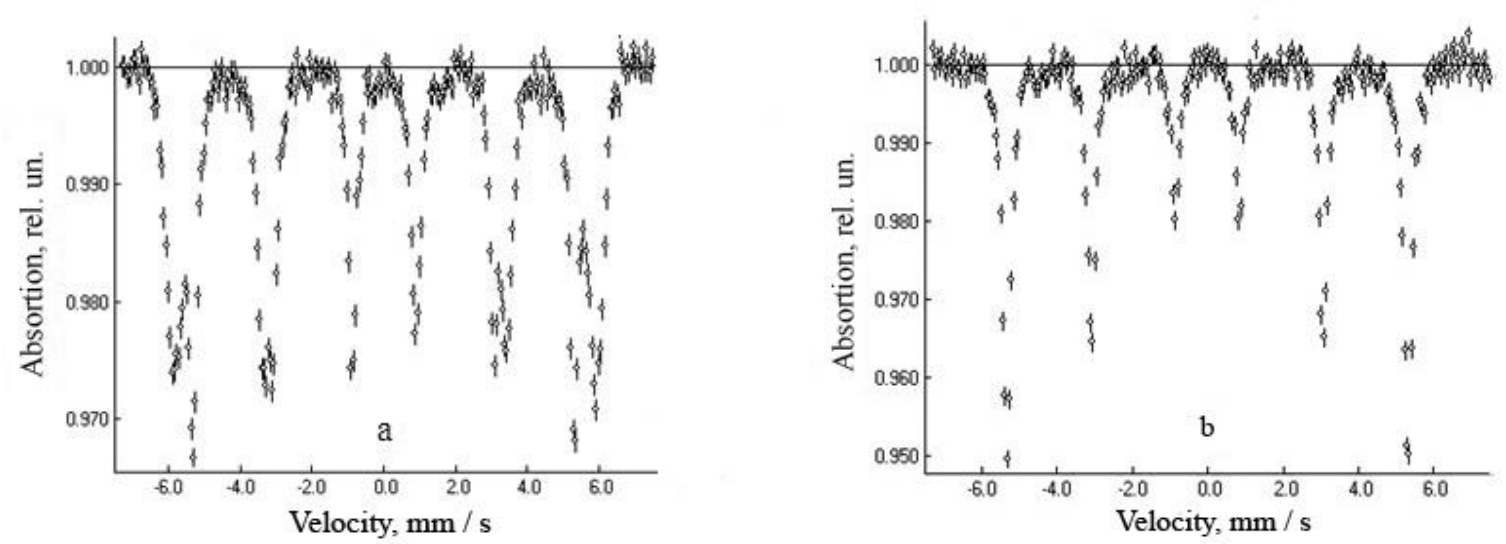

Figure 3. Mössbauer absorption spectra of samples of ultrafine iron with a prticle size of $50 \mathrm{~nm}$ (a) and $35 \mathrm{~nm}$ (b). Source: R. Lass (2006). 
An analysis of spectra of powder sample with a particle average size of $50 \mathrm{~nm}$ provides us the following results. In the behaviour of iron powder with a particle size of $50 \mathrm{~nm}$ pronounced anomalies were observed: immersion of the sample in liquid nitrogen for 24 hours did not lead to any changes in the Mössbauer spectrum measured at room temperature, compared with the initial state. But if the spectrum measurement was carried out at $77 \mathrm{~K}$ (i.e. the simultaneous influence of low temperature and gamma radiation), the range changed. After this complex influence within 24 hours, the Mössbauer spectrum of this same sample changes, but taken at room temperature. After exposure of the same sample during the year to air at room temperature spectrum taken at $300 \mathrm{~K}$, changed again. The results of the analysis of Mössbauer spectra of powder sample with a particle average size of $50 \mathrm{~nm} \mathrm{Fe}$ depend on the conditions from the shooting mode and pre-exposure (measurement mode range; intensity of the effective magnetic fields $\mathrm{H}$, share component in the spectrum, \%):

1. $\mathrm{T}=300 \mathrm{~K} ; \mathrm{H}=365 \mathrm{kOe}(48,4 \%) ; \mathrm{H}=330 \mathrm{kOe}(50 \%)$; Doublet (1,6\%); ( Fig.4 a).

2. $\mathrm{T}=77 ; \mathrm{H}=371 \mathrm{kOe}(49 \%) ; \mathrm{H}=336 \mathrm{kOe}(44 \%) ; \mathrm{H}=485 \mathrm{kOe}(5 \%) ; \mathrm{H}=330 \mathrm{kOe}(2 \%)$; (Fig. 4c).

3. $\mathrm{T}=300 \mathrm{~K}$; after $77 \mathrm{~K} ; \mathrm{H}=365 \mathrm{kOe}(47 \%) ; \mathrm{H}=330 \mathrm{kOe}(51 \%)$; Doublet $(2 \%)$.

4. $\mathrm{T}=300 \mathrm{~K}$; after gamma-irradiation at $77 \mathrm{~K}$ and aging for 1 year at $300 \mathrm{~K} . \mathrm{H}=364 \mathrm{kOe}(63 \%) ; \mathrm{H}=329$ kOe (34\%); $\mathrm{H}=467 \mathrm{kOe}(2 \%) ; \mathrm{H}=450 \mathrm{kOe}(1 \%)$; (Fig.4d).

5. $\mathrm{T}=300 \mathrm{~K}$; Sample from the N- pole of magnet; $\mathrm{H}=365 \mathrm{kOe}(56 \%) ; \mathrm{H}=330 \mathrm{kOe}(41 \%)$; Doublet (3\%).

6. $\mathrm{T}=300 \mathrm{~K}$; Sample from the S- Pole of magnet; $\mathrm{H}=363 \mathrm{kOe}(52 \%) ; \mathrm{H}=329 \mathrm{kOe}(45 \%)$; Doublet (3\%).

In (Baldokhin \& Petrov, 1992) paramagnetic poorly resolved singlet erroneously attributed to the "frozen" high-temperature antiferromagnetic spin structure. Measurements made in liquid nitrogen, showed that actually it was a doublet from highly dispersed oxides, which at $77 \mathrm{~K}$ became a sextet with the $\mathrm{H}=485$ kOe. At $\mathrm{T}=4 \mathrm{~K}$ the oxide should eventually stabilize.

Nature field with the $\mathrm{H}=365 \mathrm{kOe}$ that in (Baldokhin \& Petrov, 1992) (according to the Weiss theory) explains the "frozen" high-temperature ferromagnetic spin structure also remains outstanding. In Baldokhin and Petrov (1992) it was also wrongly alleged that the number of phases with the $\mathrm{H}=365$ kOe increased after high-temperature annealing, i.e., approaching with increasing temperature to its "original state" in FCC structure. To increase the resolution on the two sextets iron speed range was chosen to average out the background. This helped to resolve the two sextets with the $\mathrm{H}=330 \mathrm{kOe}$ and $365 \mathrm{kOe}$ in the initial spectrum of the particles, but worsened the situation for the powder heated at $800{ }^{\circ} \mathrm{C}$ for 30 minutes and rapidly cooled to $20^{\circ} \mathrm{C}$. The particles of the speckle pattern, one line of the sextet has osirisis, a field of $\mathrm{H}=365 \mathrm{kOe}$ disappeared, because the effective fields distribution began to occupy the range $\mathrm{P}(\mathrm{H})=250-450 \mathrm{kOe}$, there was a component of the spectrum of the "slack wire", responses with oxide nanostructures with a large spread of particle size. In (Hayashi et al., 1980) almost the same range of powder of $10 \mathrm{~nm}$ iron obtained at $300 \mathrm{~K}$ showed on the measurement at $80 \mathrm{~K}$ the presence of magnetite.

A similar phenomenon (but with a predominance of oxides) occurred during annealing of evaporated particles of the alloy Fe-Co and other systems received and later published in (Baldokhin, 1998). The percentage of phase with the $\mathrm{H}=365 \mathrm{kOe}$ would be altered by magnetic separation of the powder in $\mathrm{N}$ and S-poles of two different magnets, but also with temperature measurement.

Therefore we can assume that we are dealing with a new state of nanogels due to size effects. It should be noted that in $\mathrm{BCC}$ iron with particle size less than $7 \mathrm{~nm}$ instead of the hyperfine field with the $\mathrm{H}=330 \mathrm{kOe}$ occurs superparamagnetic doublet. As we observed, a new ultrafine structure of this doublet did not appear. Baldokhin, Petrov et al. (Baldokhin et al., 1995, 1998) using gas evaporation obtained aerosol particles of a number of alloys of different composition: Fe-Ni, Fe-Mn, Fe-Pt, Fe-Ni-Mn, Fe-Co, Fe-Cr. However, in most researches, especially on the evaporation of alloys $\mathrm{Fe}-\mathrm{Co}$ and $\mathrm{Fe}-\mathrm{Cr}$, the samples were heavily oxidized, the composition of the particles does not correspond to the original composition of the 
alloy, there was segregation, clusters of individual components of the alloys, and, after sampling had been received, a small number of substances.
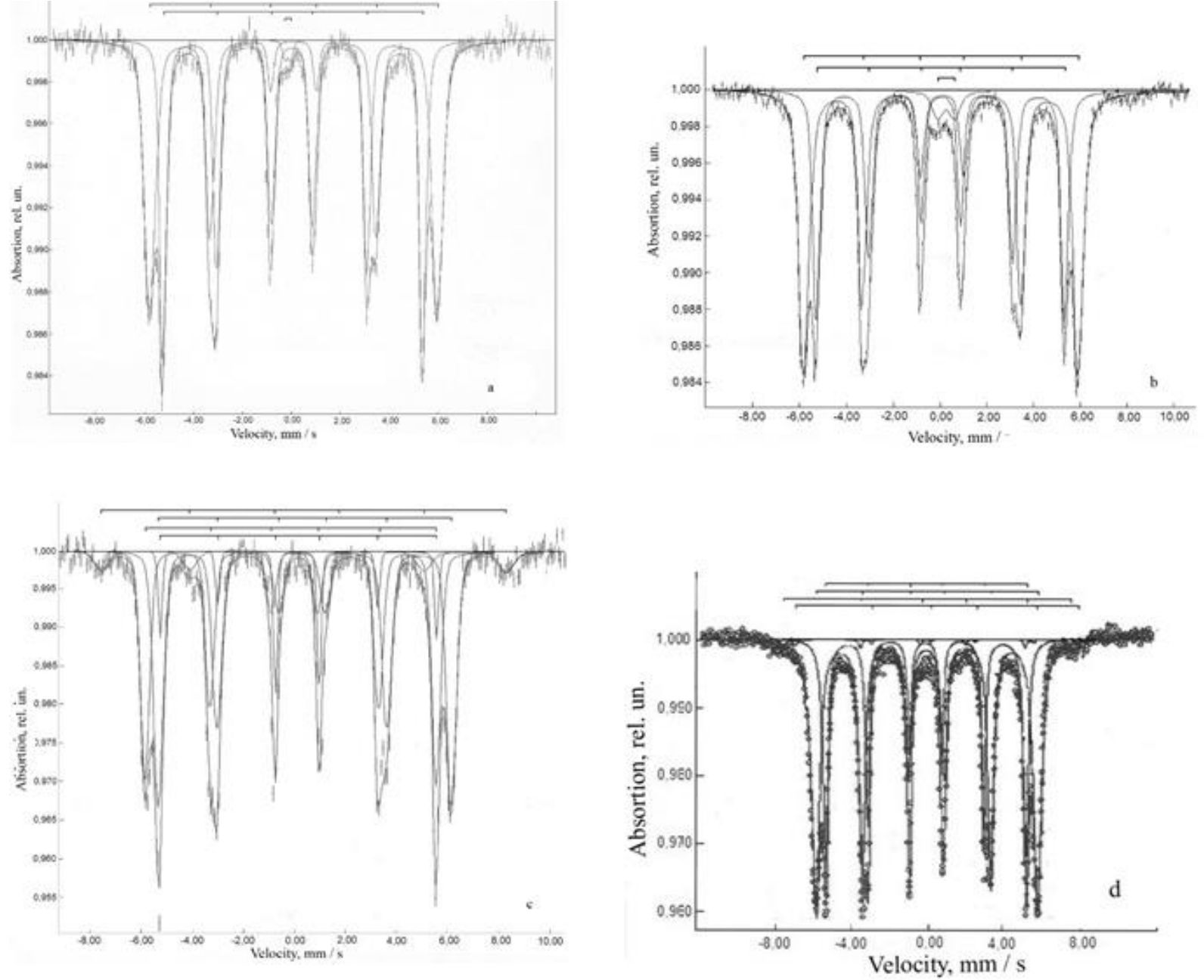

Figure 4. Mössbauer spectra of samples of ultrafine iron with a particle size of $50 \mathrm{~nm}$ : a) aging in air for 20 years, b) spectrum at $300 \mathrm{~K}$ after magnetic separation of the powder, c) measurement in liquid nitrogen, d) is aging at room temperature for a period of one year after measurements in liquid nitrogen.

Experimental spectra were difficult for mathematical processing. There were also fields $\mathrm{H}=345-350 \mathrm{kOe}$ in aerosol particles of Fe-Ni-Mn (Petrov, Shafranovsky \& Baldokhin, 2000). For sample Fe $34.65 \mathrm{Mn}$ spectrum was hard, which was derived by additional, a new phase with the $\mathrm{H}=350 \mathrm{kOe}(17 \%)$ (Baldokhin et al., 1995). There were phase with the $\mathrm{H}=353 \mathrm{kOe}(75 \%)$ and the phase with the $\mathrm{H}=323 \mathrm{kOe}(25 \%)$ in foil BCC alloy Fe3Pt of $4 \mu \mathrm{m}$ thickness, isomeric shifts in these phases were $0.16 \mathrm{~mm} / \mathrm{sec}$ (Baldokhin et al., 1998).

During the magnetite formation (in aerosols after evaporation of the alloy Fe - Co alloys and other) possible electron exchange between ions $\mathrm{Fe} 2+$ and $\mathrm{Fe} 3+$ and General electronic configuration and electron orbitals can change, because magnetite is "coating" the iron particles.In (Akai, 1991) the hyperfine field and the isomer (chemical) shifts for alloys $\mathrm{Fe}-\mathrm{X}(\mathrm{X}=\mathrm{Sc}, \mathrm{Ti}, \mathrm{V}, \mathrm{Cr}, \mathrm{Mn}, \mathrm{Co}, \mathrm{Ni}, \mathrm{Cu})$ in disordered alloys calculated using the Korriuga-Kolin-Rostoker coherent potential approximation (KKR-CPA) in combination with the functional theory local density. As a result, trend overlap concentration dependences of the Heff on the iron cores of a number of alloys is derived, qualitatively explaining the contributions of local, exchange, transfer (transferred) interactions. 

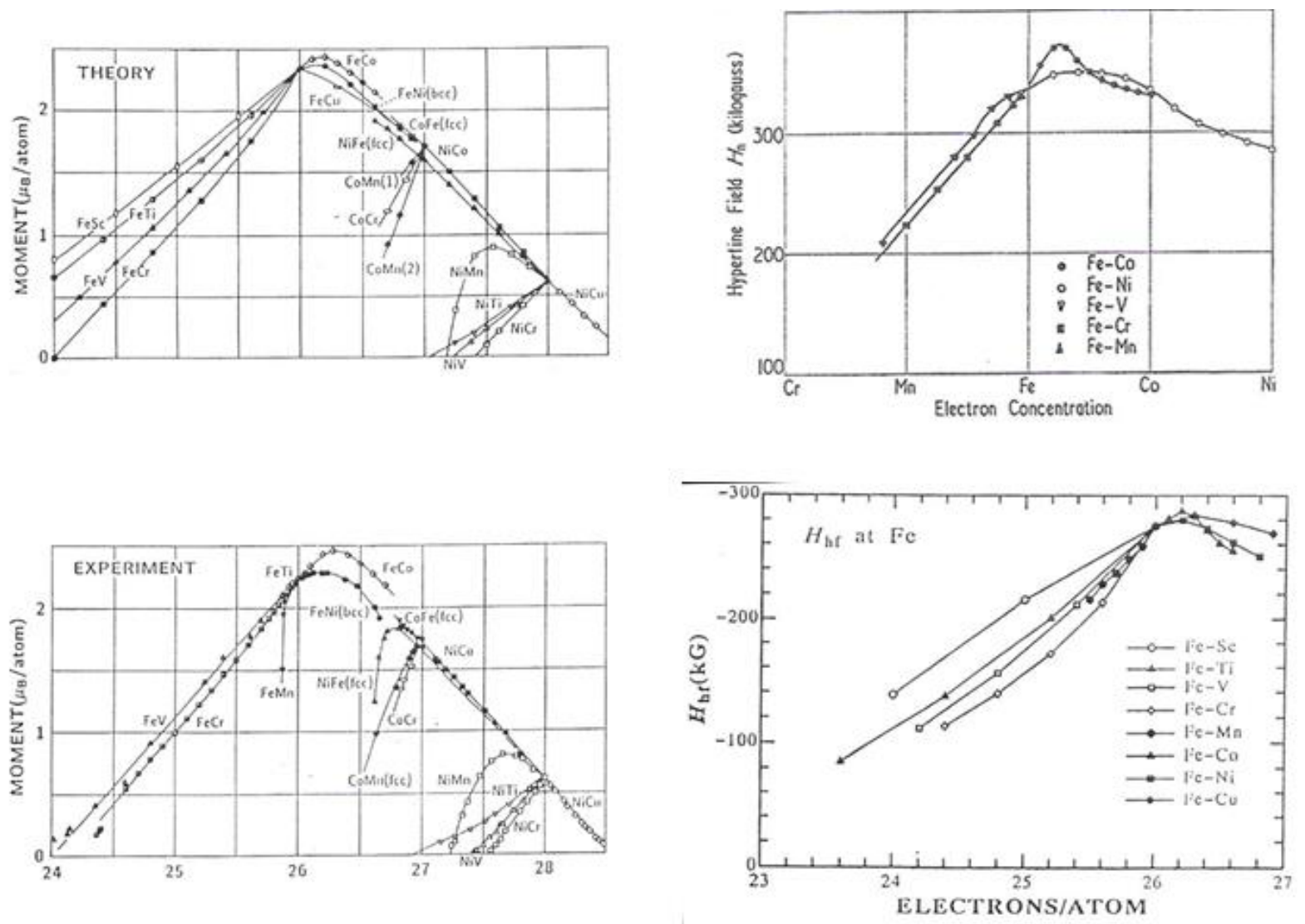

Figure 5. The calculated and experimental data of the magnetic moments of alloys based on $\mathrm{Fe}-$, $\mathrm{Ni}-$, $\mathrm{Co}-$, etc., depending on the concentration of electrons per atom of the element.

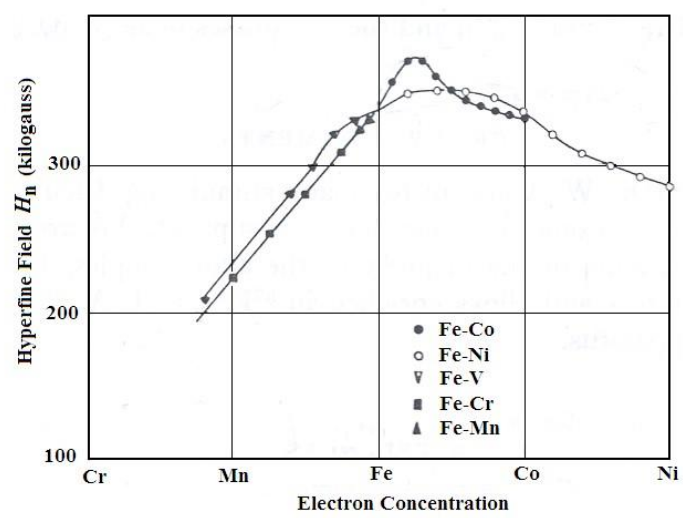

Figure 6. The change of the hyperfine field at the 57Fe nucleus, depending on the concentration of electrons per atom of the element element

Fig. 5 and 6 present the summary results graphs obtained in (Akai,1991; Johnson, Ridout \& Cranshaw, 1963). The maximum field at the iron nuclei (mentioned earlier the field $\mathrm{H}=365 \mathrm{kOe}$ ) is obtained by 26.2 per electron per atom. The same field at the same time meets in Fe65Co35 alloy (Baldokhin, et al., 1998a). 
Fields for the above-mentioned alloys can also be found in these dependencies. The magnetic field $\mathrm{H}=$ $365 \mathrm{kOe}$ also meets in $\alpha-\mathrm{FeOOH}$ (Baldokhin et al., 2012). Therefore, it is necessary that a more thorough study of the phenomen should be performed.

Samples of nanopowders were measured of iron $(35 \mathrm{~nm}$ and $50 \mathrm{~nm})$ on a transmission electron microscope JEM-2100 F, Jeol, Japan. Images of the sample with an average particle size of $35 \mathrm{~nm}$ does not fundamentally differe from the described in the literature and represented particles of different sizes $(10-200 \mathrm{~nm})$.

Samples from the conditional average (by X-ray data) of size $50 \mathrm{~nm}$ Fe were measured with different resolution (about 50 pictures) from different sites of the sample. And they all differed. Pictures of TEM (Fig.7) present some of them in the scale of $100 \mathrm{~nm}, 10 \mathrm{~nm}, 2 \mathrm{~nm}$. In addition to the usual Fe particles (black areas) with size 10-200 $\mathrm{nm}$ the picture shows the grey areas of different configurations of twisted traces (paths), which were deposited particles.
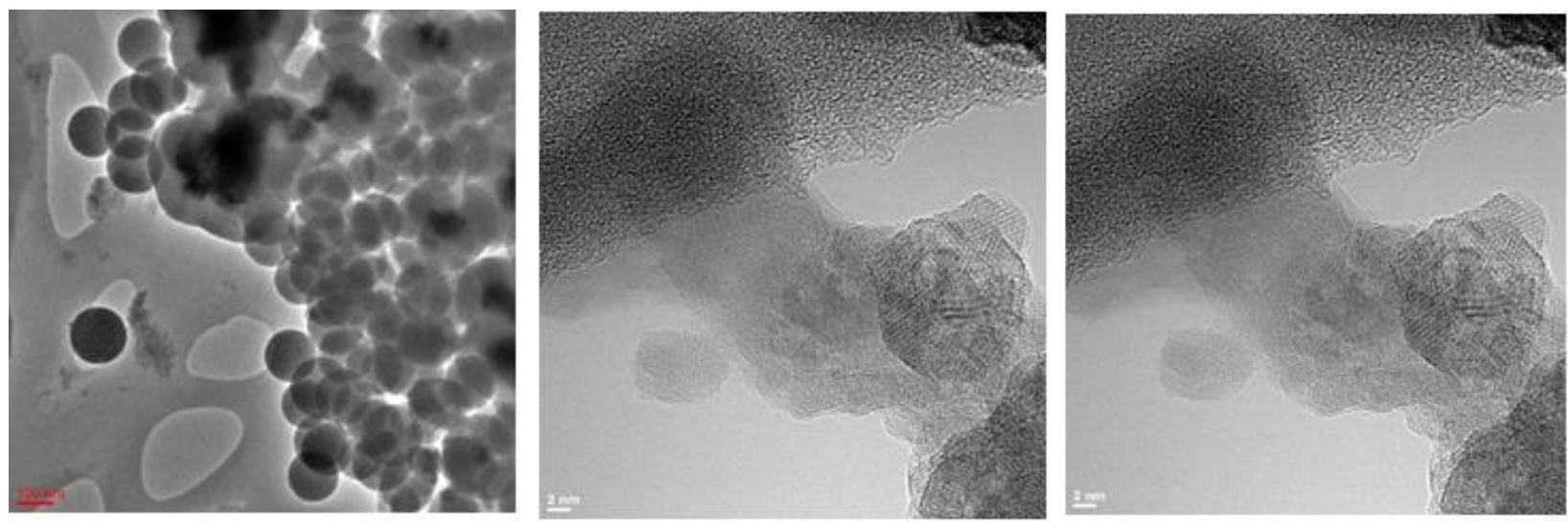

Figure 7. Electron-microscopic image of the iron powder with a nominal average size of $50 \mathrm{~nm}$. Photos are taken with different scale.

Width of tracks were from $50 \mathrm{~nm}$ to $200 \mathrm{~nm}$. Tracks permeate the entire powder nanogels $50 \mathrm{~nm}$. The percentage of paths on the images varies, but the average number is close to $50 \%$. Inside the grey formations, the tracks do not repeat again flat segregation, clusters-"patterns" (monolayers of iron atoms). This iron is not the BCC, because the monolayer has no crystal lattice. Crossing tracks clusters are not enlarged, visible separately one below the other. This new structure is not three-dimensional and twodimensional close-packed, filled with very small particles and very reminiscent of the rolled out carpet. All of these structures do not repeat in form, isolated, "live by themselves". The new structure, bringing together the atoms of iron creates a molecular field that will interact with neighbouring particles that have already established a regular for iron box with $\mathrm{H}=330 \mathrm{kOe}$. And the particles of $50 \mathrm{~nm}$-iron (as Mössbauer spectra) are very sensitive to temperature, magnetic, and other external influences. According Prigogine, these "patterns" are due to the new state of nanogels, finding the minimum free energy, self-organization, the formation of the new structure, after which exchange interactions will create a new field with the $\mathrm{H}=365 \mathrm{kOe}$.

Of course, it is impossible to ignore the above-described resulting oxide structures effect, which may, depending on their content, increase the total number of electrons per atom of iron to 26.2 (between Fe and Co), which, according to (Akai, 1991), will also provide the field with the $\mathrm{H}=365 \mathrm{kOe}$. It should be noted that prolonged aging at room temperature results in improved resolution of two hyperfine structures and in their percentage content changing in the Mössbauer spectra. We also need to consider magnetic hyperfine fields formation mechanism at the nuclei of a typical ferromagnet, which is iron. In the scheme of filling of iron atoms electronic shells unfinished d-shell has 4 unpaired electrons, which determine the magnetic moment. 
In an isolated iron atom, orbital motion of electrons creates some orbital moment. However, during the crystalline state formation, the orbital moments are "frozen" by intracrystalline fields and contribute to the magnetic moment of iron atoms.

The reason for this is still unclear. However, the experiments clearly indicate that the orbital moments are not involved in the ferromagnetism of transition d-elements. Moreover, gland in the distribution of valence electrons in different energy levels is influenced by many factors, so we cannot say a priori, in what condition are external $3 \mathrm{~d}$ - and 4 s-electrons.

From measurements of the magnetization of saturation it is known that the magnetic moment of iron atoms in the metal is to 2.86 per Bohr magneton. However, the characteristic time of measurement during static and dynamic methods of measurement of magnetic characteristics are different, i.e. sometimes the magnetic parameters do not coincide in the different measurements techniques. For example, Mössbauer spectra finest new delay amorphous-crystalline alloys Finemet not to change during annealing in a wide range of temperatures and times of annealing, and macromagnetic characteristics are dramatically changing. Lifetime of the excited state of the Mössbauer nucleus of iron is approximately 100 nanoseconds, which allows to investigate the local environment, the middle and far right, the transmission processes of the electron density.

The magnetic field at the iron nuclei from their own electrons can be represented in the form of three contributions: the contact of the magnetic interaction of electrons with the nucleus, the so-called Fermi contact interaction; the interaction of the orbital magnetic moments of the electrons with the nucleus; the interaction of the intrinsic magnetic moments of electrons with a magnetic moment of the nucleus. If the oxides are present in the samples, ions of two and three valent iron will be available. There are 4 electrons with uncompensated spins in the $3 \mathrm{~d}$ shell of divalent iron ion, trivalent iron ion of these five electrons. Accordingly, the magnetic moment of bivalent iron is 4 Bohr magneton, and trivalent - 5 Bohr magnetons. If there are nanoparticles of non-stoichiometric magnetite in shell, the transfer of electron density between the 2-and 3-valent iron ions is possible. This can polarize the electrons in the shells of neighbouring iron nanoparticles atoms which are often annodomini, i.e. have the maximum energy. The total (orbital and spin) angular momentum of the electron shells of iron $(\mathrm{H}=330 \mathrm{kOe})$ should influence on neighbouring molecular field "patterns".

Based on local interactions of neighbouring atoms and the magnetic state of the sample with $50 \mathrm{~nm}$ of pure iron, $\mathrm{BCC}$ lattice of iron with $\mathrm{H}=330 \mathrm{kOe}$ will impact on a flat, single layer formation of iron nanoparticles again, but in new condition, in which there is no three-dimensional crystal lattice (X-ray studies showed the presence of only one BCC structure), i.e. there will be a contribution of the orbital moments of electrons. The magnetic field from the orbital moment of the $3 \mathrm{~d}$ electrons is several tens of $\mathrm{kOe}$ and coincides in direction with the external field (so its value can also give supplement to normal field of iron $\mathrm{H}=330 \mathrm{kOe}$ to the value of the field in $365 \mathrm{kOe}$ ). Field of electronic spins 3d-shell, considered as a field of magnetic dipoles, is about $10 \mathrm{kOe}$ and has the same sign.

All of the above reasons may cause formation of new structure of iron with $\mathrm{H}=365 \mathrm{kOe}$.

\section{CONCLUSIONS}

The causes that influence the form and parameters of the Mössbauer spectra of iron nanopowders are obtained by the Gen- Miller;s method. Levitation evaporation of high-purity iron in an inert atmosphere method allowed us to obtain nanopowders, which along with iron, having a field on nuclei $\mathrm{H}=330 \mathrm{kOe}$, correspond to massive $\mathrm{Fe}$, there was a particle with a field $\mathrm{H}=355-365 \mathrm{kO}$. The first two fields were detected with the use of computer calculation of Mössbauer spectra. But after more than 20 years aged, aging powders at $300 \mathrm{~K}$ was a clear separation of the spectrum of two of the sextets. The percentage sextet 
also changed during annealing and magnetization of the nanopowder samples. Simple immersion of samples in liquid nitrogen quenching and further measurement at $300 \mathrm{~K}$ has not changed the percentage of phases.

Only the temperature of liquid nitrogen and a simultaneous removal of the spectrum within two days changed the nanostructure. Radiochemical processes happened in the accumulation of a certain dose of gamma-irradiation from Mössbauer radioactive source. The spectra obtained for samples with different average particle sizes were compared. The results related to size effects differ from the researches of other authors.

Apparently, some of the observed effects can be explained by influence of border phenomena, interface structures at the grain boundaries. Using transmission electron microscopy it was revealed that nanoparticles with a mean (X-ray data) particle size of $50 \mathrm{~nm}$ have also Angstrem patterns, which can meet the new structure. Using Mössbauer spectroscopy we revealed a new iron with nanostate field $\mathrm{H}=$ $365 \mathrm{kOe}$ at $300 \mathrm{~K}$, which differs from the bulk iron. Presence of small amounts of superparamagnetic oxide could be a catalyst, impetus for the formation of the new structure, and also, at the exchange interactions, could modify the charge of the electron density at the Fe nuclei. Reviewed and other factors can result in appearing of such a high value of the effective magnetic field at the iron nuclei. The maximum field at the iron nuclei is $\mathrm{H}=365 \mathrm{kOe}$, according to theoretical researches, at 26.2 per electron per atom. The same field $\mathrm{H}=365 \mathrm{kOe}$ meets the in $\alpha-\mathrm{FeOOH}$ and Fe65Co35 alloy. This convergence of fields, of course, requires further experiments, studies of the influence of size and interface, the edge effects.

The analysis of the reasons for the existence of new state nanogels is not the ultimate truth and, of course, requires a deeper theoretical understanding.

\section{REFERENCES}

Akai, H. (1991). Hyperfine field calculation for various alloy systems. Hyperfine Interactions,68, 3-14.

Baldokhin, Yu. V., Cherdyntsev, V. V., Kaloshkin, S. D., \& Tomilin, I A. (1998a). Hyperne structure of alloys of the iron-cobalt, prepared by mechanical alloying. Reports of Academy of Sciences, 1(1), 8-40.

Baldokhin, Yu. V., Kolotyrkin, P. J., Petrov, Yu. I., \& Shafranovskii, E. F. (1995). Structure and Mössbauer spectra of the ultra-small particles of iron-enriched alloys Fe-Mn. Reports of Academy of Sciences, 344(4), 465-468.

Baldokhin, Yu. V., Kolotyrkin, P. Ya., Makarov, V. A.; Petrov, Yu. I., \& Shafranovsky, E. A. (1998). Phase transitions and local crystallographic magnetic ordering of Fe3Pt. Phase Transitions, 64, 239-247.

Baldokhin, Yu. V., \& Petrov, Yu. I. (1992). Two States of FCC-structure of the iron found in the study of Mössbauer spectra and thermal expansion of small particles. Reports of Academy of Sciences, 327 (1), 8791.

Baldokhin, Yu. V., Suzdalev, I. P., Prusakov, V. E., Burnazyan D. A., Korneev, V. P., Kovalenko, L. V., \& Folmanis, G. (2012). A study of the hydrogen reduction of $\mathrm{Fe}(\mathrm{OH})_{3}$. Russian Journal of Phisical Chemistry B, 6(1), 81-88.

Del Bianco, L., Hernando, A., Bonetti, E., \& Navarro, E. (1997). Grain-boundary structure and magnetic behavior in nanocrystalline ball-milled iron. Physical Review B, 56(14), 8894-8991. 
Campbell, S. J.; Chadwick, J.; Pollard, R. J.; Gleite, H.; \& Gonser, U. (1995). Nanostructured Fe and FePd studied by Mössbauer spectroscopy. Physica B, 205, 72-78.

Hayashi, M.; Tamura, I.; Fukano, Y.; Kanemaki, S.; Funo, Y. (1980). Mössbauer effect study of lattice vibration of small iron particles. Phisic C: Solid. St. Phys., 13, 681-688.

Herr, U., Jing, J., Birringer, R., Gonser, U. \& Gleiter H. (1987). Investigation of nanocristalline iron materials by Mössbauer spectroscopy. Appl. Phys. Lett, 50 (8), 472-474.

Johnson, S. E., Ridout, M. S., \& Cranshaw, T. E. (1963). The Mössbauer Effect in Iron Alloys. Prog. Phys. Soc., 81, 1079-1090.

Petrov, Yu. I., Shafranovsky, E. A. (2001). Exhibition of high-and low-spin states of the high temperature fcc phase in nanoparticles of Fe Fe-rich and Co-rich alloys. Journal of Nanoparticle Research, 3, 419-432. Petrov, Yu. I., Shafranovsky, E. A., \& Baldokhin, Yu. V. (2000). Structure and local magnetic order in ultrafine particles of Fe65(Ni1-xMnx)3 $(0<\mathrm{x}<1)$ alloys. Solid State Communications, 113,153-158.

Pollard, R. G., \& Chadwick, J. (1994). Distinguishing nanocrystalline solids from fine-particle ensembles using Mössbauer spectroscopy. Hyperfine Interactions, 94, 2245-2248.

\section{SEMBLANCE OF THE AUTHORS}

Yuriy V. Baldokhin: He is a Candidate of Physical and Mathematical Sciences, senior researchers, Structure of Substance Department, Institute of Chemical Physics RAS

Yuriy D. Perfiliev: He is a Full Doctor of Chemical Sciences, Lomonosov Moscow State University, Chemical Department,

Leonid A. Kulikov: He is a Full Candidate of Chemical Sciences, Lomonosov Moscow State University, Chemical Department 